\title{
AMOR E CONJUGALIDADE NA CONTEMPORANEIDADE: UMA REVISÃO DE LITERATURA
}

Leandro Castro Oltramari*

\begin{abstract}
RESUMO. O presente artigo se propõe a realizar uma revisão bibliográfica sobre a temática do amor e da conjugalidade no mundo contemporâneo trazendo contribuições de autores como Bozon, Gagnon e outros. O amor tem sido uma temática de discussão diversificada das ciências humanas e sociais e principalmente da Psicologia. A perspectiva adotada neste trabalho apresenta as contribuições da sociologia da sexualidade em uma revisão que traz o amor como uma perspectiva de interação social vivenciada como sentimento amoroso. Esta análise centra-se principalmente na teoria dos roteiros sexuais, compreendendo o amor como uma prática social, mas vivenciada como sentimento. Esta forma híbrida constitui uma das principais características do amor na contemporaneidade.
\end{abstract}

Palavras-chave: Amor; roteiros sexuais; conjugalidade.

\section{CONTEMPORARY LOVE AND CONJUGALITY: A LITERATURE REVIEW}

\begin{abstract}
The purpose of this article is to provide a bibliographic review about the theme of love and conjugality in the contemporary world including contributions from authors such as Bozon, Gagnon and others. The theme of love has been discussed not only in human and social science but particularly in psychology. The perspective adopted in this work presents contribution from the sociology of human sexuality. Its revision demonstrates love as a social interaction perspective experienced as a loving sentiment. The analysis focuses basically on the sexual scripts theory, which understands love as a social practice although lived as a feeling. This hybrid form consists in one of the main characteristics of contemporary love.
\end{abstract}

Key words: Love; sexual scripts; conjugality.

\section{AMOR Y CONYUGALIDAD EN LA CONTEMPORANEIDAD: UNA REVISIÓN LITERARIA}

RESUMEN. La propuesta del presente artículo es realizar una revisión bibliográfica sobre el tema del amor y la conyugalidad en el mundo contemporáneo, trayendo contribuciones de autores como Bozon, Gagnon entre otros. El amor ha sido un tema de discusión de las ciencias humanas, sociales y principalmente de la psicología. La perspectiva adoptada en este trabajo trae contribuciones de la sociología de la sexualidad. Esta revisión coloca el amor como una perspectiva de interacción social vivenciada como sentimiento amoroso. Este análisis se centra principalmente en la teoría de los scripts sexuales, comprendiendo el amor como una práctica social vivenciada como sentimiento. Esta forma hibrida constituye una de las principales características del amor en la contemporaneidad..

Palabras clave: Amor; scritps sexuales; conyugalidad.

Historicamente, o amor tem sido, durante séculos, um dos mais declamados, procurados ou mesmo desejados sentimentos relacionados ao comportamento humano. Por muitas vezes referenciado como uma das razões de viver, ou de sofrer, ele tem sido responsabilizado tanto pelas felicidades humanas quanto por suas mazelas. Em face disso, este artigo propõe-se a fazer uma revisão das leituras contemporâneas sobre o amor na literatura nas ciências humanas. Pretende-se, aqui, fazer uma discussão crítica a partir da ideia do amor como sentimento para chegar-se à questão central do texto, que é compreendê-lo a partir do mundo contemporâneo no campo das ciências humanas.

* Doutorado Interdisciplinar em Ciências Humanas. Professor Titular da Universidade do Vale do Itajaí e Universidade do Sul de Santa Catarina. 


\section{A VIVÊNCIA DO SENTIMENTO AMOROSO}

Existem várias perspectivas para compreender o amor. Para iniciarmos esta análise, vamos partir de um clássico sobre o assunto: o livro de Dennis de Rougement (1939/2003). Este pensador suíço, nascido no ano de 1906, escreveu a obra A história do amor no ocidente, publicada em 1939 e considerada, por muitos autores, uma das mais importantes do século XX sobre a temática do amor. Para realizar sua análise, o autor partiu do mito de Tristão e Isolda. Em seu estudo, revelou que a ideia de amor reinante em nossos dias é relativamente nova, tendo surgido em torno do século XII e estando fortemente marcada por características ocidentais. Isso não quer dizer que não existia relação integrada entre o afeto e a sexualidade, como nos revela o pensamento grego a partir da leitura de Foucault (1998, 1999); mas o que é significativo aqui é que, a partir do século XII, o amor passa a ter uma identidade que lhe dá certa autonomia e liberdade com relação às interações sociais. A partir desse momento, parece que o amor não necessitava de outros ingredientes. Ele bastava a si mesmo.

O "amor romântico" se constitui, assim, como aquele que nunca alcança a correspondência, continuando como uma busca contínua. É ainda Borges (2004) que cita o exemplo do romance de Tristão e Isolda, a mesma obra analisada por Denis de Rougement, apontando que, nesse mito, o amor é percebido como uma doença da alma, que pessoas como Isolda, personagem do romance, decidem contrair. Podemos perceber isso a partir do que os estoicos pensavam sobre o amor.

Segundo Freire Costa (1998), estas informações são importantes para podermos compreender que hoje se vive com base em concepções do amor romântico que fazem uma "mistura de ilusão e realidade, de ganhos e perdas, de avanços, paradas e recuos no campo das relações humanas" (1998: 150). Assim, o amor, segundo o autor, "é suporte de predicação moral" (Idem: 161) e tanto pode representar felicidade quanto sofrimento.

Vale ressaltar que a ideia de amor não correspondido é a tônica dos principais romances da cultura ocidental. Para Borges (2004), a literatura amorosa representa uma grande contribuição para entender como o amor é compreendido na Modernidade. A autora usa como exemplo a obra de Goethe Os sofrimentos do jovem Werther, que, segundo ela, foi causadora de inúmeros suicídios no século XVIII. Tal livro trata da dor de um amor não correspondido.
Ainda segundo Borges, a ideia contemporânea de amor surge do pensamento grego, que pressupõe três tipos de amor: Eros, philia e caritas. Eros é originado do pensamento platônico e lembra o amor romântico, aquele que talvez seja o mais próximo deste conhecido atualmente. Este tipo de amor está ligado à falta, ou seja, ao sofrimento. Seria aquele amor que busca ser alcançado. Já o amor philia está próximo ao pensamento de Aristóteles e encontra-se relacionado a um desejo de partilhar a companhia do outro, principalmente se for através da virtude. É querer o bem do outro. Por último, o amor ágape ou caritas, que está mais próximo da philia, é um amor que está atrelado ao bem do outro, muito próximo do humanismo cristão. Assim, gostar de alguém seria amar esta pessoa incondicionalmente e só lhe fazer o bem. O amado nada mais é, para o amante, que alguém a quem ele deseja fazer o bem.

É possível perceber aqui uma relação entre as características que Rougement define para o amor romântico e as atribuições que Borges estabelece ao que Platão chamara de Eros. Isso ocorre porque, segundo Rougement (2003), o amor cortês foi constituído a partir de uma "idealização do amor carnal". Ele faz relações que demonstram que o amor cortês tem uma influência mística ou mesmo religiosa. Por exemplo, em alguns poemas de trovadores que cantavam o amor à mulher amada, esta era comparável a Deus, à perfeição. Este ponto pode ser identificado no texto de Macfarlane (1990) quando, citando o poeta inglês John Milton, que viveu entre 1608-1674, revela que este aponta que a perda de Adão e Eva do direito de viver no paraíso não foi devida à "insubordinação" em comer o fruto proibido, mas sim, ao ato de Adão colocar Eva acima de Deus; ou seja, o amor fê-lo escutar a amada, e não a Deus. Assim podemos identificar que Rougement defende que "o amor-paixão glorificado pelo mito foi realmente, no século XII - data de sua aparição -, uma RELIGIÃO na mais plena acepção do termo e especialmente UMA HERESIA CRISTÃ HISTORICAMENTE DETERMINADA" (2003: 192; grifo do autor).

Outro autor que também dissertou sobre o amor foi o sociólogo Georg Simmel, que viveu entre 1858 e 1918. Ele elaborou fragmentos de textos organizados em uma obra chamada Filosofia do amor, na qual realizou uma discussão abordando o amor a partir do egoísmo. Para Simmel, o amor é um sentimento que se atrela mais diretamente ao seu objeto, ou seja, o objeto amado. Ele se estabelece de uma forma que, quando consolidado, descarta o aspecto central que o mediou, sendo percebido como um acontecimento transcendental a si mesmo. Assim, veremos que o 
amor é, na maioria das vezes, percebido como algo transcendente à sua própria existência, ou seja, à relação na qual ele surgiu. $O$ sujeito que ama defende o autor - tem a impressão de que a vida dele está única e exclusivamente mediada pelo amor do sujeito amado e a serviço dele. Simmel ainda faz uma reflexão importante, pois, segundo ele, no amor há uma condição trágica que promove, entre os sujeitos, a necessidade de fundir-se com a pessoa amada, de modo a constituírem uma só pessoa. Ele postula tais questões a partir de princípios sociológicos, pois descarta a ideia do amor com motivações apenas biológicas.

Vale dizer que esta ideia de amor transcendental, descrita por Simmel, é muito comum com relação ao sentimento amoroso. Podemos identificar tal associação em pesquisas sobre coup de foudre realizadas por Marie-Noelle Schurmans e Loraine Dominicie (1997). Elas pesquisaram o que seria, para os brasileiros, a ideia de "amor à primeira vista", ou seja, arrebatador e quase místico. De acordo com esta concepção, o amor vem de algum lugar que não se consegue identificar e é vivido de forma intensa em relação a alguém específico.

Em outro estudo de Simmel (1909/2001), publicado originalmente em 1909 e chamado $A$ psicologia do coquetismo, o autor faz a relação do amor entre o "ter e o não ter". Ele também revela que o amor se configura como um esgotamento quando se realiza; ou seja, quando o amante possui o objeto amado, o amor passa a não existir mais. $\mathrm{O}$ autor revela que o amor é tanto mais buscado quanto mais difícil se torna realizá-lo (mais uma vez, a imagem do amor inalcançável atrelado ao sofrimento se faz presente). Para a conquista do objeto amado, ele observa que homens e mulheres relacionam-se a partir do que ele denomina coquete. $\mathrm{O}$ autor descreve o coquetismo como uma forma específica de homens e mulheres estarem um em relação ao outro, de maneira que se sintam mutuamente atraídos ou atraentes. O significado do coquetismo tem uma relação direta com tornar-se desejável ao outro, através de gestos ou mesmo de comportamentos. O coquetismo seria o jogo de sedução elaborado pelos amantes para fazer desencadear ou despertar o sentimento do amado. É isso que possibilita que as pessoas sintam interesse por outra pessoa e a amem.

Continuando a discussão sobre o "amor à primeira vista" a partir da pesquisa de Schurmans e Dominicie (1997), elas afirmam que estas lógicas de pensamento do coup de foudre expressam formas de dar respostas religiosas, ou mesmo por meio de crenças e de magias, para explicar o mundo em que se vive. As autoras utilizam Jung para concluir que o amor está ligado a uma relação de autonomia e de troca. Para tais autoras, a paixão revela uma forma de fazer o sujeito valorizar o objeto amado e desvalorizar-se a si próprio e, assim, tornar a relação fusional, já que na "paixão" existe uma abolição de limites entre o amado e amante.

No estudo de Schurmans e Dominicie (1997), as referidas autoras chegaram à conclusão de que o amor à primeira vista é vivido, muitas vezes, como sentimento benéfico ou maléfico. $\mathrm{O}$ início do encontro é percebido como maravilhoso, mas as dificuldades que o relacionamento apresenta posteriormente vão determinando uma mudança de imagem. Os entrevistados relataram o amor à primeira vista como algo que acontece como um flash, algo instantâneo. Muitas vezes, em suas pesquisas ele esteve relacionado à irracionalidade ou a sentimentos incontroláveis.

O amor vira "objeto em si mesmo". Isso pode ser identificado na obra Fragmentos de um discurso amoroso, publicada originalmente em 1977 pelo filósofo, escritor e semiólogo francês Roland Barthes. Este autor revela que, por vezes, na anulação, característica de um dos fragmentos deste discurso amoroso, o amor se torna um fenômeno procurado pelos amantes que resulta em uma anulação pessoal quando acreditam que o encontram. Para o autor, existe, portanto, uma relação de dependência com o objeto amado. Os amantes sentem uma sensação de ausência de realidade quando amam.

\section{O AMOR COMO UMA PRÁTICA SOCIAL}

A segunda abordagem explicitada aqui será aquela que relaciona o "amor" a uma prática social exercida através do que denominamos roteiros sexuais. A perspectiva dos roteiros sexuais, defendida por Gagnon (2006; 1999) e por Simon e Gagnon (1986; 1984), aborda a constituição da sexualidade e do desejo, assim como o amor, a partir de uma relação de roteirização destes fenômenos. Assim, eles defendem que as pessoas irão amar outras porque existe uma condição social e cotidiana que dá possibilidades para que isto ocorra.

Para compreender o "amor" como um roteiro sexual, utilizaremos uma abordagem desenvolvida pelo sociólogo Michel Bozon (2005), segundo o qual existem várias visões sobre o amor, encontradas principalmente na literatura. Para ele, importante é compreender que o amor se constitui como fenômeno prático cujo sentido se encontra em um jogo. Ele é um ato de conceder a si mesmo ao outro. Bozon cita Luhmann, para quem o amor age como "um código 
geral de comunicação, que cria os fundamentos da intimidade contemporânea, relações intersubjetivas e de um domínio da intimidade" (Bozon, 2005, p. 2).

Destarte, vale dizer que existe uma relação constituidora do "amor" a partir das mais variadas interações sociais que o conduzem a uma ação prática, mas que ele é, sim, vivenciado como um sentimento. Por isso é inegável que, dentro do mundo contemporâneo, existe uma relação direta com o que pensamos e com o que concebemos sobre o amor, a partir de sua vivência como sentimento. Dessa forma, ele se institui no interior de uma série de roteirizações (Gagnon, 2006) que nos levam a sentirmo-nos atingidos pelo amor de alguém ou a tocar o coração de outra pessoa. Vale, não obstante, lembrar que isso acontecerá nas relações interpessoais que denominamos práticas sociais.

Bozon (2005) afirma que a compreensão do que seja o amor deve partir da ideia de uma prática social, cotidiana, de um roteiro. Uma das primeiras ações definidoras deste contexto são as informações ou trocas de confidências quando as pessoas estão se conhecendo Os amantes vão concedendo a pequenos gestos, como envio de fotos, de pequenas cartas (hoje e-mails), entre outros, que, de uma forma mais consistente, irão constituindo a relação amorosa não como algo místico, mas sim, como uma construção passo a passo, na interação de um com o outro.

Vale dizer que as pesquisadoras Schurmans e Dominicie (1997), citadas anteriormente, identificaram as estratégias amorosas como coletivas e inconscientes. As dinâmicas coletivas forjam os habitus, que possibilitam que os sujeitos tenham interesse uns pelos outros. Elas ainda citam o italiano Alberoni (1994) para relatar que ele trata a paixão como uma constituição do "nós", ou seja, uma dimensão interpessoal por excelência.

É por isso que, para Barthes (2003), toda relação amorosa é um drama, pois o encontro é o evento fundador de um possível "amor" que será constituído e que poderá ser longo ou curto, dependendo do tipo de relação que será estabelecido. Desta forma, o encontro, que é a primeira fase do "amor", parece mágico, pois acontece antes de se sucederem os conflitos e os confrontos intrínsecos ao relacionamento amoroso.

Barthes (2003) revelou a importância do papel da comunicação na roteirização do laço amoroso. Ele ilustra isso quando refere que a carta de amor é uma forma esvaziada, mas, ao mesmo tempo, cheia de sentido para a expressão do amor. Por exemplo, a carta de amor faz com que o sujeito ao qual ela é endereçada se sinta amado e, ao mesmo tempo, cobrado a responder a ela. Assim, a comunicação é uma dimensão interpessoal que auxilia na constituição do sentimento amoroso. Com isso, entendemos que esses pequenos gestos configuram a constituição da prática amorosa.

Seguindo ainda o raciocínio de Bozon, o sociólogo alemão Niklas Luhmann, que foi aluno de Jurgen Habermas, em seu texto Amour comme passion, originalmente publicado em 1982, diz que o amor é uma relação de comunicação interpessoal e social entre as pessoas. Ele não deve ser compreendido, ou mesmo tratado, como sentimento; é um código simbólico que informa sob que condições o sujeito irá amar outra pessoa. $\mathrm{O}$ autor revela que o amor passa a ser percebido como uma fonte de informações, e não mais como uma invenção mental. O que se pensa hoje sobre o amor é que constitui um sentimento que existe antes mesmo de os sujeitos encontrarem um parceiro, pois há um código partilhado, que é construído anonimamente por todas as pessoas e é comum a todos. Para Lhumann, o amor "permite ao outro dar alguma coisa precisamente sendo tal como ela é” (Luhmann, 1990, p. 40).

\section{AMOR E REFLEXIVIDADE}

Luhmann (1990), assim como Giddens (1993), faz menção à reflexividade na contemporaneidade, que propicia a individualização das relações entre as pessoas e do sentimento amoroso. Para Giddens (1993), tais relações individualizadas são as causas do fracasso do casamento fundado no amor, pois uma das características que ele define como um dos sucessos dos relacionamentos reflexivos seria a necessidade de uma diferenciação entre as pessoas, ou seja, um respeito por sua individualidade. Já para Luhmann (1990), o problema do individualismo é um impasse dentro da modernidade, pois, de maneira geral, as pessoas compreendem que o amor deve ser vivido de maneira a ser atrelado ao imaginário do amor romântico, e assim o fazem em uma busca gradativamente intensa. Por exemplo, a autora Purificacion Gomes (1992) revela que o amor tem sido cada vez mais procurado dentro dos relacionamentos de conjugalidade. A autora revela que grande parte das dissoluções conjugais acontece porque o amor "acaba", mas logo as pessoas entram em novos relacionamentos, procurando o amor que terminou no anterior.

$\mathrm{O}$ individualismo talvez demonstre um paradoxo dentro da relação entre individualidade e autonomia que se encontra hoje nos laços de conjugalidade. Segundo Giddens (1993), os laços de intimidade estão 
mais atrelados ao que chamamos hodiernamente de relacionamentos amorosos. $\mathrm{Na}$ contemporaneidade essa expressão tem mais sentido do que a própria ideia de casamento. $\mathrm{O}$ autor, apesar de fazer uma distinção entre o amor romântico e o amor passion, deixa transparecer que $\mathrm{o}$ amor romântico incorporou elementos do amor passion, como, por exemplo, uma busca pelo sujeito amado sempre com expectativas de que os sentimentos do início do relacionamento se perpetuem. Vale dizer que o amor romântico acaba sendo novo dentro da história do amor, já este sempre se diferenciou da paixão. Podemos compreender que na Modernidade existe uma relação direta entre essas duas formas de relacionamento, porquanto, se entendermos que o amor passa a ser direcionado não mais apenas ao companheirismo, mas também ao prazer atrelado à sexualidade, amor e paixão se aproximam muito.

\section{A CONJUGALIDADE NA CONTEMPORANEIDADE}

A conjugalidade no mundo contemporâneo está sendo abordada por alguns autores, dentre eles Giddens (1993) e Bauman (2004), que tratam das incertezas que a modernidade trouxe aos relacionamentos amorosos. Segundo os autores, as pessoas sentem a necessidade de buscar vínculos amorosos materiais em uma sociedade que coloca dificuldades nas constituições dos vínculos sociais.

Para Zygmunt Bauman (2004), na Modernidade os laços afetivos se tornam cada vez mais frágeis, o que decorre das crescentes relações de consumo características de nosso contexto histórico; mas o autor também afirma que, mesmo dentro desta fragilidade, existe uma necessidade de relacionamento entre as pessoas - estes relacionamentos apenas estão mais rápidos e menos cristalizados do que em tempos atrás. Ele se refere à metáfora do "amor líquido" como uma forma de compreender a complexidade das relações afetivas do ser humano na atualidade. Apesar das características efêmeras do amor, é interessante perceber quanto ainda este é almejado como se fosse eterno, mesmo sabendo-se que poderá durar menos do que imaginamos. Como a insegurança causa mal-estar, podemos compreender que as pessoas envolvidas em relacionamentos amorosos tentam controlá-los como se controlam investimentos realizados no mercado.

Sobre o amor na Modernidade, por exemplo, Luhmann (1990) revela que, para ser amor e diferenciar-se de sentimentos como a paixão mais vil, é necessário tempo de relacionamento, segurança e algo que o torne mais estável; mas o grande problema, segundo o mesmo autor, é que assim o amor destrói a si mesmo. Vale explicar que isso acontece porque o amor e a paixão se constituem como lados da mesma moeda dentro da Modernidade, tendo o casamento como seu fim, apesar de a história mostrar que nem sempre eles andam juntos. Segundo o autor, enquanto o amor procura serenidade, a paixão procura aventuras; porém, o amor se constitui dentro de uma lógica de busca por uma institucionalização. Segundo a psicóloga social Vergas Silva,

O amor romântico é uma prova social da capacidade ímpar humana de significar e dar sentido a fenômenos. Estas representações se manifestam em palavras, sentimentos e condutas que se institucionalizam, e que, assim, regularizam e impõem nossa forma de amar (Silva, 2005, p. 3933).

Assim podemos compreender que, para a existência de uma relação de conjugalidade, o amor é estabelecido por meio da "confiança" entre os parceiros. Desta forma, Silva (2005) revela que a "confiança" é um dos requisitos fundamentais para a realização do amor. Sem ela, não há possibilidade de relacionamento institucionalizado. As pessoas vivem com o desejo quase indissolúvel da fidelidade como uma instância única de realização do amor romântico. A certeza de que o eleito é "único" e "eterno" é muito forte nesta perspectiva. O imaginário romântico concebe a ideia de indissolubilidade dos amantes. Silva revela que o amor, mesmo na sociedade ocidental, é sentido de forma idealista.

Para Anthony Giddens (1991), a "confiança” é um fenômeno necessário à sociedade moderna, pois esta deriva das transformações das relações sociais. Para ele, a confiança só existe em uma relação de risco, e o sujeito tem de estar consciente deste. Segundo o autor, se este sujeito não consegue prever ou considerar os riscos existentes nas relações sociais, mantém um comportamento de crença, pois esta pressupõe que elementos que são familiares permaneçam estáveis. Sem percepção dos riscos presentes na relação, "um indivíduo que não considera alternativas está numa situação de crença, enquanto alguém que reconhece essas alternativas e tenta calcular os riscos assim reconhecidos se engaja em confiança" (Giddens, 1991, p. 39). Podemos, porém, pensar que a "confiança" pode ser um tipo de crença, e alguns pontos podem ser considerados para

\footnotetext{
A confiança é uma categoria muito utilizada para designar uma das estratégias dos casais para diferenciar os relacionamentos "sérios" daqueles sem menor importância.
} 
revelarmos por que a "confiança" se consolida na Modernidade. Quando há uma ausência no tempoespaço, as pessoas necessitam confiar em algo que não é visível. Outra questão importante é que a confiança se relaciona à credibilidade que uma pessoa tem na relação com outra. É esta credibilidade proporcionada pelo outro que possibilita estabelecer-se a confiança. No caso da conjugalidade, parece ser esta a forma de estabelecimento da confiança. Assim, é possível compreender, a partir do autor, que dentro das relações de conjugalidade a confiança está relacionada com uma possibilidade de risco aceitável para as pessoas, desde que não se desestruturem as relações sociais entre elas e aqueles com quem se relacionam. Quando confia, a pessoa pode calcular um risco e saber de sua ameaça. Confiando-se, pode-se estabelecer um comportamento de segurança diante dos riscos. A segurança, aqui, é delimitada como "uma situação na qual um conjunto específico de perigos está neutralizado ou minimizado" (Idem, p. 43).

Então o "amor" será, segundo Freire Costa (1998), o que ele chama de "crença emocional", assim como Giddens (1991) define a "confiança" como quase atrelada à ideia de uma "aposta". A ideia de crença emocional é fundamental para compreendermos as relações no interior da conjugalidade. Estas "emoções amorosas", sentidas quando se está no "calor" do relacionamento, são vividas como reais, e essa realidade é que impulsiona os sujeitos a pensarem no amor como algo transcendental, vivido de forma imortalizada pelos que estão envolvidos. Esta emoção é experienciada como julgamentos irrefletidos, e faz com que os amantes sintam possuir a mesma identidade do companheiro, já que o amor permite aos sujeitos dar estabilidade a algo que é instável, como se caracterizam hoje as relações sociais. A partir desse momento, compreenderemos que na Modernidade o amor se constituirá como um importante elemento para a conjugalidade. $\mathrm{O}$ amor, para Freire Costa, é uma invenção que nada mais fez do que tornar os seres humanos caçadores deste suposto sentimento. Em tempos contemporâneos as pessoas se sentem fracassadas quando não encontram alguém para amar, ou ainda quando encontram e mas o amor não se constitui como o desejado; ou seja, o amor é um tipo de objetivo que o ser humano contemporâneo tende a nunca encontrar. Ainda assim é interessante pensar que esta insegurança ou "desesperança" não leva as pessoas a desistirem dele, ao contrário, faz com que cada vez mais ele seja buscado.

Destarte, para compreender como os laços afetivo-sexuais se formam, é necessário percebê-los dentro de um leque de interações sociais. Para Freire Costa (1998), o amor não é mágico; ele é seletivo, da mesma forma exposta por Bozon (2001a) quando se refere à homogamia. Esta questão é importante, pois se vive o amor de forma espontânea, de modo que quanto mais ele for sentido desta forma, mais ele é considerado puro. Ambos os autores descrevem o amor como uma experiência que se faz através de uma lógica prática, como qualquer outra que imprimimos em nossa vida - ou seja, escolhemos amar os iguais, pessoas que compartilhem as mesmas identidades que as nossas, possuindo os mesmos gostos e identificando-se com características similares às de quem se ama.

Vale lembrar que autores como Bozon (2004b) indicam que as relações de conjugalidade têm se mostrado cada vez mais atreladas ao que ele compreende como homogamia, a qual é formada a partir de similares condições sociais e existenciais e implica na união entre sujeitos que possuem grande afinidade socioafetivo-intelectual. $O$ casamento constitui, a partir da homogamia, um "mecanismo poderoso de cristalização das clivagens sociais" (Schurmans \& Dominicie, 1997, p. 93).

Segundo Foucault (1999), o vínculo conjugal, para os gregos, era associado a uma relação de ajuda mútua e de companheirismo, além da procriação; mas os gregos já compreendiam que o casal era uma forma de unificação dos cônjuges, principalmente porque o casamento era descrito como uma prática cotidiana de encorajamento e de cumplicidade entre eles. Podemos, dessa maneira, identificar que o casamento era o lugar da legitimidade do ato sexual, o que não significa que ele fosse o único espaço em que a relação sexual pudesse acontecer.

\section{CONJUGALIDADE E AMOR: OS DILEMAS DA MODERNIDADE.}

Partindo destas concepções, devemos compreender que a sexualidade do casal não se constitui senão como um cenário cultural no qual os sujeitos têm referências para agir sobre a realidade. Podemos dizer que existe uma forma - que Bozon (2001b) chama de orientações íntimas - pela qual a sexualidade irá conformar-se. Para o autor, "as orientações íntimas constituem verdadeiros quadros mentais que delimitam o exercício da sexualidade, definindo o sentido que lhe é dado e indicando o papel da sexualidade desempenhado dentro da construção de si” (Bozon, 2001b, p. 13, tradução nossa).

Como a sexualidade passa por mudanças, assim como o amor, devemos compreender que os laços de 
conjugalidade decorrem de um momento de complexificação das relações amorosas. Apesar de ter ocorrido uma mudança significativa nas relações entre homens e mulheres, ainda se percebe que não se pode falar de igualitarização dos seus papéis, e isso ajuda a compreender as formas complexas como a conjugalidade vêm constituindo-se, isto é, sob um contexto de permanência dos valores e das tradições concomitantemente dom suas mudanças, assim como de transformações das identidades e dos papéis sexuais. Um exemplo citado por Bozon (2001c) refere-se a uma pesquisa de Daniel Welzer-Lang sobre o mundo swing ${ }^{2}$. O pesquisador revela que $o$ fenômeno swing fez diminuir o interesse dos homens pela prostituição, porque estes utilizam suas esposas para ter acesso a outras mulheres. Tal prática não se tornou necessariamente uma forma mais igualitária de relações entre homens e mulheres, pois muitas destas se submetem a ela por imposição do companheiro.

Dessa maneira, conforme Bozon (2001a, 2004a), a sexualidade do casal na Modernidade se conforma melhor a um modelo de sexualidade individual, que está cada vez mais presente nos cotidianos sexuais. Ele tece tal afirmação levando em conta que o desejo individual é a marca da sociedade contemporânea. As relações sexuais hoje se configuram mais de forma narcísica que altruísta, mas ainda assim existem representações que constroem, para o casal, a ideia de que os limites entre as duas pessoas podem acabar, de que os integrantes não têm mais diferenças entre si. É o que ocorre, por exemplo, com a ideia do casal fusional (Heilborn, 2004). Isso se dá porque, segundo o autor, pode haver orientações íntimas contraditórias a partir dos diferentes espaços que ocupam as pessoas que se relacionam.

Essas "relações íntimas", citadas por Bozon anteriormente, podem ser compreendidas a partir da psicóloga social Sharon Brehm (1991). Segundo essa autora, existe uma necessidade de compreensão das relações íntimas como uma forma de interação social que ela identifica como troca; ou seja, existem, segundo ela, recompensas, custos e troca social em qualquer relação que suponha algum tipo de intimidade. As recompensas são classificadas por determinados atributos, como as características físicas do companheiro, beleza, inteligência, assim como a atenção dispensada pelo companheiro ou ainda o auxílio prestado em algum momento da vida. Os recursos também podem ser financeiros, inclusive em

Swing é uma palavra conhecida no Brasil para designar o que se conhece popularmente como "troca de casais". Na França, os autores chamam de L'echangisme. determinados tipos de relação. Os casais, portanto, estabelecem redes de relações nas quais os laços íntimos se constituem a partir dessas características de trocas.

É claro que essas redes de relações vão sendo constituídas dentro de um universo de interações, que é complexo, com intensas aproximações e afastamentos entre as pessoas que se relacionam conjugalmente. Por exemplo, Brehm diz que a relação do casal se caracteriza por atribuições sobre o que um pensa em relação ao outro e, ainda, sobre o relacionamento entre ambos. Segundo ela, o relacionamento conjugal é percebido como uma troca íntima de comunicação entre as pessoas.

O que mais caracteriza a intimidade, segundo Brehm (1991), é o fato de as relações de intimidade, que se intitulam amor, surgirem dentro dos aspectos de comunicação interpessoal. $\mathrm{O}$ amor se estrutura a partir daí. A comunicação tem uma importante tarefa, que é o revelar-se ao outro. Ela argumenta que existe, para os amantes, um abrir-se ao outro, para mostrar-se quem é. De alguma forma, a exposição faz com que se alimente a confiança entre as pessoas. Podemos afirmar, mediante as informações elencadas, que as relações de intimidade dentro da conjugalidade estabelecem o que podemos compreender como um contrato. Não se trata, entretanto, de um contrato pela tradição, mas sim, de um contrato pela vontade de estar junto com o outro. Segundo Bozon (2001c), o casamento é um contrato contínuo que prevê o envolvimento dos companheiros. $\mathrm{O}$ amor e o sexo têm papel primordial dentro desse contrato.

Segundo Kaufmann (2003), a sexualidade e o amor acabam tomando uma dimensão exponencial na vida do casal conjugal moderno. As pessoas ainda colocam o amor como um valor; elas podem interessar-se por várias pessoas, mas não amar mais que uma. Em outras palavras, as pessoas vivem a exclusividade no relacionamento amoroso. Dessa forma, o autor revela que o discurso sobre o amor dentro da conjugalidade é realizado através da ideia de devoção. Ele ainda revela que os sujeitos aparecem amando mais o amor que o objeto amado, porque o amor é percebido como sendo de definição inqualificável.

Kaufmann (2003) também afirma que estamos longe de romper com a ideia de amor como algo transcendental no contexto das relações conjugais. $\mathrm{O}$ amor conjugal parece ser um sentimento vivido hibridamente entre a personificação daquele que o vive e o sentimento em si. $\mathrm{O}$ amor materializou-se como mito a partir de representações históricas; ele assim se constituiu como um sentimento, 
principalmente a partir da conjugalidade. Vale ressaltar que o sentimento amoroso se inscreve em uma relação identitária entre aqueles que amam.

Estudos de Psicologia Social de Endo, Heine \& Lehman (2000) sobre conjugalidades e identidades revelam que existe uma característica comum subjacente aos discursos das pessoas que vivem relacionamentos afetivos amorosos em países ocidentais: elas consideram suas relações de modo mais positivo do que as relações de outras pessoas. Para os entrevistados, portanto, suas relações sempre são melhores que as dos outros. As mulheres pesquisadas compreenderam seus relacionamentos afetivos familiares como positivos mais do que os homens.

Dessa forma, podemos pensar que o estabelecimento daquilo que os casais compreendem por confiança nada mais é do que esta forma de tentar controlar o incontrolável, pois esta não possibilidade de previsão sobre o outro impossibilita a vida das pessoas, já que a dúvida é uma constante na vida do casal. O ser humano procura por segurança ante a imprevisibilidade da vida e tenta fugir da fragilidade dos laços do mundo moderno. Isto quer dizer que, segundo Apostolidis e Deschamps (2003), como vimos anteriormente, os relacionamentos de conjugalidade estabelecidos nos dias de hoje se dão a partir de uma relação prazerosa. Assim sendo, compreendemos a existência de uma diferença entre a vivência e a não vivência da conjugalidade. É que os sujeitos estabelecem relações de conjugalidade e perspectivam a construção de um projeto de vida em comum com aqueles que elegem como amados, enquanto aqueles que vivenciam relacionamento sem conjugalidade não o elaboram.

\section{CONSIDERAÇÕES FINAIS}

O presente trabalho apresentou uma revisão bibliográfica sobre o amor dentro da perspectivas de autores contemporâneos, que o têm compreendido não como um sentimento, mas como uma prática social construída através de roteiros sexuais que se constituem no universo social e interpessoal dos amantes. A principal constatação na literatura consultada aponta para aquilo que se pode identificar como uma hibridização das concepções de amor; ou seja, o amor ainda tem fortes componentes do elemento romântico, mas incorpora cada vez mais elementos daquilo que no passado foi chamado de amor paixão. Assim as pessoas continuam procurando as emoções da paixão com a segurança que o amor traz por meio da confiança. Talvez seja esta dupla função incorporada pelo amor no mundo contemporâneo o que tem trazido descontentamento e ao mesmo tempo sua busca incessante. Pode-se assim dizer que o amor tem apresentado uma "roupagem nova" para ainda permanecer no centro dos interesses e buscas do ser humano. Ele não perdeu sua força. Hoje ele é mais importante do que era em tempos atrás. Talvez ele tenha se tornado mais central do que o era nos tempos de Sheakspeare e sua obra clássica Romeu e Julieta.

\section{REFERÊNCIAS}

Alberoni, F. (1994). Lê Vol Nupticial: l'imaginaire amoureux dês femmes. (P. Girard, Trad.). Paris: Plonm.

Apostolidis, T; Deschamps, J.-C. (2003). Une Approche Psychosociale De L'amour: Logiques normatives et représentations. Dans Nouvelle Revue de Psychologie Sociale, 2(2) 216-227.

Barthes, R. (2003). Fragmentos de um Discurso Amoroso. (M. V. M. de Aguiar, Trad.) São Paulo: Martins Fontes.

Bauman, Z. (2004). Amor Líquido: sobre a fragilidade dos laços humanos. (C. A. Medeiros, Trad.). Rio de Janeiro: Jorge Zahar Editor.

Borges, M. L. (2004). Amor. Rio de Janeiro: Jorge Zahar Editor.

Bozon, M. (2004a). A nova normatividade das condutas sexuais ou a dificuldade de dar coerência às experiências intimas. Em Heilborn, M. L. (Org.), Família e sexualidade. (pp.119-150). Rio de Janeiro: FGV

Bozon, M. (2001a) Les cadres sociaux de la sexualité. Dans Sociétés contemporaines. 41-42, 5-9.

Bozon, M. (2001c) Sexuality, gender and the couple: a sociohistorical perpective. In Annual Review of sex research, (12) 1-30.

Bozon, M. (2005). Supplément à um post-scriptum de Pierre Bourdieu sur l'amour ou peut-on um théorie d'amour comme pratique (mimeo).

Bozon, M. (2004b). Sociologia da sexualidade. Rio de Janeiro: FGV.

Bozon, M. (2001b). Orientations intimes et construtions de soi. Pluralité et divergences dans les expressions de la sexualiaté . Em Sociétés contemporaines. 41-42, 11-40.

Brehm, S. (1991). Las relaciones intimas. Em Moscovici, S. (Org.). Psicologia social I. (pp.211-236). Barcelona/Buenos Aires/México: Ediciones Paidós.

Endo, Y, Heine, S. J, Lehman, D. R. (2000). Culture and Positive Illusions in Close relationships: How My Relationships Are Better Than Yours. In Personality And Social Psychology Bulletin. 12(26) December, 1571-1586.

Foucault, M. (1999). História da sexualidade: a vontade de saber. Rio de Janeiro: Graal.

Foucault, M. (1998). História da sexualidade: o uso dos prazeres. Rio de Janeiro: Graal. 
Freire Costa, J. (1998). Sem fraude nem favor: estudos sobre o amor romântico. Rio de Janeiro: Rocco.

Gagnon, J. H. (1999). Les uses explicites et implicites de la perspective des scripts dans les recherches sur la sexualité. Dans Actes de la recherche em scienes sociales, 128, 7379.

Gagnon, J. (2006). Uma interpretação do desejo: ensaios sobre o estudo da sexualidade. (L.R. da Silva, Trad.). Rio de Janeiro: Garamond.

Giddens, A. (1993) A transformação da intimidade: sexualidade, amor e erotismo nas sociedades (M. Lopes, Trad.). São Paulo: UNESP

Giddens, A. (1991). As consequências da modernidade. (R. Finker, Trad.). São Paulo: Editora UNESP.

Gomes, P. B. (1992). Separação - contingência do casamento? Em Porchat, I. (Org.), Amor, casamento, separação: a falência de um mito. (pp. 127-144). São Paulo: Brasiliense.

Heilborn, M. L. (2004). Dois é par: gênero e identidade sexual em contexto igualitário. Rio de Janeiro: Garamond.

Kaufmann, J-C. (2003). Sociologie du couple. Paris: PUF.

Luhmann, N. (1990). Amour comme passion: de la codification de l'intimite. Paris: Aubier.

Macfarlane, A. (1990). História do casamento e do amor. (P. Neves, Trad.). São Paulo : Companhia das Letras.
Rougement, D. (2003). História do amor no ocidente. (P. Brandi, E. B. Cachapuz, Trad.). São Paulo: Ediouro.

Schurmans, M-N, \& Dominicie, L. (1997). Lê coup de foudre amoureux: essaide sociologie compreensive. Paris: Press Universitaires de France.

Silva, V. V. A. (2005). Pra que rimar amor e dor: um estudo sobre as formas contemporâneas de representação e expressão do sofrimento amoroso. Em III Jornada Internacional de Representações Sociais - João Pessoa/PB. (pp. 3931-3940). IV Jornada Internacional e II Conferência Brasileira sobre Representações Sociais.

Simmel, G. (2001). Filosofia do amor. São Paulo: Martins Fontes. (Original publicado em 1909).

Simon, W, Gagnon, J. H. (1986). Sexual scripts: permanence and change. In Archives of sexual behavior. 2(15), 97-120.

Simon, W, Gagnon, J. H. (1984). Sexual scripts. In Society, 5360.

Recebido em 24/03/2008 Aceito em 21/10/2008

Endereço para correspondência : Leandro Castro Oltramari. Rua das Azaléias, 1606, Bosque das Mansões, CEP 88108-400, São José-SC, Brasil.E-mail: leandrooltramari@gmail.com 
